\title{
Review
}

\section{Can pigeonpea hybrids negotiate stresses better than inbred cultivars?}

\author{
Kul Bhushan Saxena ${ }^{\dagger 1}$, Arbind K. Choudhary*²), Rachit K. Saxena ${ }^{\dagger 1)}$ and Yashvir S. Chauhan ${ }^{\dagger 3)}$ \\ 1) International Crops Research Institute for the Semi-Arid-Tropics (ICRISAT), Patancheru 502 324, Telangana, India \\ 2) ICAR Research Complex for Eastern Region, Patna 800 014, Bihar, India \\ 3) Department of Agriculture and Fisheries, Kingaroy, Queensland 4610, Australia
}

Pigeonpea [Cajanus cajan (L.) Millsp.] is an important rainfed pulse crop of tropics and sub-tropics, and during its long growth cycle of 6-9 months it encounters a number of biotic and abiotic stresses. The recently developed CMS-based pigeonpea hybrids have demonstrated large gains in yield and stability over the traditional inbred cultivars. In this review, the authors argue that the heterosis expressed in traits like seed germination, radicle growth, root biomass production and moisture retention during water stress confers advantages to hybrid plants in negotiating a few abiotic and biotic stresses in much better way than pure line cultivars.

Key Words: pigeonpea, heterosis, radicle, root biomass, water stress, adaptation, abiotic stresses.

Introduction

The potential of a cultivar is primarily determined by its genetic constitution, but the quantum of harvest is directly influenced by various soil and environmental stresses. Prevalence and intensities of these stresses in the vicinity determine the losses they inflict on the final yield. Agricultural droughts generally occur due to either low rainfall over a sustained period or significant changes in rainfall patterns. Such droughts are prevalent in non-irrigated areas where plants' water resource is entirely dependent upon rains (WorldAtlas 2019). Under these agricultural situations, pigeonpea [Cajanus cajan (L.) Millsp.] grows well due to its inherent root qualities and ability to recover from drought (Saxena 2008). Since pigeonpea is invariably cultivated as a rain-dependent crop and remains in field for 6-9 months, the drought (early season, late season and/or intermittent) is considered the most common yield constraint. The non-availability of donor genotypes and precise screening techniques makes it impossible to breed drought tolerant pigeonpea cultivars in near future.

Globally, pigeonpea is cultivated on about $7 \mathrm{~m}$ ha (FAOSTAT 2019) mostly under rain-fed agriculture. As a result, its productivity is low $(700 \pm 100 \mathrm{~kg} / \mathrm{ha})$. To enhance its yield, breeders developed a CMS-based hybrid pigeonpea technology (Saxena et al. 2018). During this process a number of yield trials involving experimental hybrids were

Communicated by Norihiko Tomooka

Received January 24, 2020. Accepted March 18, 2020.

First Published Online in J-STAGE on July 3, 2020.

*Corresponding author (e-mail: akiipr23@yahoo.com)

${ }^{\dagger}$ These authors contributed equally to this work conducted in diverse environments and, in spite of various types of local stress conditions, the hybrids convincingly out-performed the inbred cultivars. In fact, there may be a number of factors which could account for hybrid excellence but the presence of hybrid vigour was the key factor. The authors in this review have tried to examine if the pigeonpea hybrids could negotiate some key stresses better than inbred cultivars and reduce the production losses.

\section{Hybrid advantage under early season drought}

Being a rain-fed crop of rainy season, the sowing time of pigeonpea is the most critical. Farmers generally sow pigeonpea with the onset of rainy season so that the crop could utilize available soil moisture for its establishment and growth. In a normal season, the seeds germinate with initial showers and soon produce radicle and plumule. This process, however, may suffer if during or soon after germination the rains stop and create a short spell of drought. Under these circumstances, some of the seedlings may wither and succumb leading to gaps in plant stand. In the following text we discuss if the hybrids can negotiate the issue of early season drought better than inbred cultivars.

Heterotic advantage in germination and early seedling growth

In the past, numerous studies on hybrid vigour in most crops were done with respect to mature plant yield components and seed yield. However, in pigeonpea little information exists on the expression of heterosis, and only three such studies were conducted involving post-embryonic development and seedling stages. Seeds with dormant embryos are activated soon after they absorb sufficient 
water. This is followed by various bio-chemical processes including cell respiration, protein/hormone synthesis, and metabolism of complex stored proteins and carbohydrates. The amino acids, hormones and simple sugars thus produced, are mobilized and used for the growth of embryo axis. The part that emerges first from the seed is embryonic root, termed as radicle or primary root and later embryonic shoot or plumule develops (Rajjou et al. 2012).

Bharathi and Saxena (2012) reported that mean germination in pigeonpea hybrids was $2.7 \%$ higher than pure line cultivars. Similarly, Thakare et al. (2013) and Mula et al. (2015) also observed significantly greater seed germination in hybrids than inbred cultivars (Table 1). Carver et al. (2014), however, did not record any hybrid advantage in pigeonpea for germination. Mercer et al. (2006) also reported higher seed germination in sunflower hybrids.

As the emerging roots grow, they develop contact with soil and start absorbing soil moisture. Initially, the seedlings use the stored food but once the primary leaves emerge they commence synthesizing their own food. To study the effects of hybridity on the growth of radicle and plumule, three experiments were conducted at ICRISAT at different times, and their results are summarized in Table 1. In 10 day old seedlings, Bharathi and Saxena (2012) reported significantly $(17.8 \%)$ longer radicle in hybrids than the inbred lines, but in contrast, the mean plumule length in hybrids was $6.1 \%$ less than inbreds. Total dry weight accumulated by the seedlings also revealed $23.69 \%$ hybrid advantage over inbred cultivars. Besides, the hybrids recorded $14.79 \%$ greater seedling vigour index than the control cultivar. Interestingly, almost similar observations were also reported by Thakare et al. (2013) and Mula et al. (2015).

In all the three studies (Table 1), the hybrids and inbred lines exhibited contrasting behaviour as far as the expres-

Table 1. Superiority of hybrids over inbred cultivars for some key seedling parameters in three experiments

\begin{tabular}{|c|c|c|c|c|c|}
\hline Genotype & Entries & $\begin{array}{c}\text { Radicle } \\
(\mathrm{cm})\end{array}$ & $\begin{array}{l}\text { Plumule } \\
(\mathrm{cm})\end{array}$ & $\begin{array}{c}\text { Dry wt. } \\
\text { (g) }\end{array}$ & $\begin{array}{l}\text { Vigour } \\
\text { index }\end{array}$ \\
\hline \multicolumn{6}{|c|}{ Study \#1 (Bharathi and Saxena 2012) 10 d after sowing } \\
\hline Inbred cvs. & 3 & 9.81 & $7.23 *$ & 3.8 & 1596 \\
\hline Hybrids & 11 & $11.56^{*}$ & 6.81 & 4.7 & $1832 *$ \\
\hline Hyb. adv (\%) & - & 17.80 & -6.10 & 23.68 & $14.79 *$ \\
\hline $\operatorname{LSD}(\mathrm{P}=0.05)$ & & 0.86 & 0.75 & 0.28 & 266.0 \\
\hline \multicolumn{6}{|c|}{ Study \#2 (Thakare et al. 2013) 30 d after sowing } \\
\hline Inbred cvs. & 3 & 9.4 & $23.6^{*}$ & 3.4 & 3036 \\
\hline Hybrids & 3 & $13.2 *$ & 20.6 & $3.9 *$ & $3570 *$ \\
\hline Hyb. adv $(\%)$ & - & 40.43 & -12.7 & 14.71 & $17.59 *$ \\
\hline $\operatorname{LSD}(\mathrm{P}=0.05)$ & & 0.9 & 0.4 & 0.5 & 279.3 \\
\hline \multicolumn{6}{|c|}{ Study \# 3 (Mula et al. 2015) 30 d after sowing } \\
\hline Inbred cvs. & 3 & 11.85 & $30.87 *$ & 3.67 & 3397 \\
\hline Hybrids & 3 & $16.75^{*}$ & 25.43 & $4.60^{*}$ & $4139 *$ \\
\hline Hyb adv (\%) & - & 41.35 & -17.62 & 25.34 & 21.84 \\
\hline
\end{tabular}

Hyb Adv: Hybrid advantage; Study \#3: LSD not reported by authors. sion of hybrid vigour in radicle and plumule was concerned. The hybrid seedlings recorded $17.80-41.35 \%$ standard heterosis in radicle growth but not in plumule, while the reverse was true for inbred cultivars. These observations demonstrated that for the expression of heterosis, different inbuilt biological mechanisms operate in hybrids and inbred lines. From these studies it can be inferred that in the hybrids, radicle was preferred sink while in the inbreds the major sink was present in the plumule tissues. Therefore, in hybrid seedlings the heterosis expresses first in the roots and later in the shoots. As a result, the hybrid seedlings produce comparatively strong root system which helps in the rapid establishment of seedlings. Hence, due to their ability to absorb relatively more moisture from soil, the hybrid seedlings can survive through the short spells of early season drought better than the inbreds. Mino (1980) also observed that the emergence of radicle in maize (Zea mays) was faster in the hybrid plants. Donaldson and Blackman (1974) reported that the rapid development of radicle in maize was a consequence of both rapid cell division as well as enlargement of individual cell size. These events at cellular level generate greater sink in radical, and to fulfil their energy requirements, relatively more food reserves are diverted from cotyledons to radicle sink. During this period, on the other hand, the plumule continues to grow at a steady pace with limited energy availability; but as soon as the primary leaves emerge, the seedlings become photosynthetically active and start expressing hybrid vigour. Heterosis may be observed in early embryo, seedling or root development (Hoecker et al. 2006, Jahnke et al. 2010). In maize, Hoecker et al. (2006) reported 24\% mid-parent heterosis for primary roots, and they attributed it to the longitudinal elongation of cortical cells. Besides this, the hybrids also expressed $51 \%$ heterosis for lateral root density and $17-25 \%$ heterosis for primary root growth.

Limited genomics studies on this aspect revealed that the main contributor to seed germination success is the quality of m-RNA that was stored during embryo maturation on the mother plant (Rajjou et al. 2012). Mino (1980) also reported that during germination large quantities of mRNA and proteins were present in hybrids. Romagnoli et al. (1990) recorded the presence of different proteins and mRNAs in the primary root tips of hybrids plants but not in the inbred parents. Dahal et al. (2012) reported that the expression of specific alleles and/or post-translational modifications of specific proteins correlated with higher levels of heterosis. According to Saeki et al. (2016), the presence of differentially expressed genes between hybrid and its parents leads to a rapid growth in different hybrid plant parts.

\section{Heterosis in advanced seedling stage}

Saxena et al. (1992) reported that between 4-7 weeks the hybrid plants exhibited significant levels of hybrid vigour over the pure line control both for roots and shoots (Table 2). The roots of hybrid plants recorded 24.21 to 
Table 2. Mean shoot and root dry weight ( $\mathrm{g}$ ) of hybrid and pure line cultivars from 30 to 50 days after sowing

\begin{tabular}{cccc}
\hline \hline DAS/part & Hybrid & Cultivar & Hybrid adv \pm SE $(\%)$ \\
\hline 30 DAS & & & \\
Shoot & $1.597^{*}$ & 1.195 & $33.64 \pm 0.19$ \\
Root & $0.407^{*}$ & 0.315 & $29.20 \pm 0.07$ \\
46 DAS & & & \\
Shoot & $4.023^{*}$ & 3.097 & $29.90 \pm 0.63$ \\
Root & $1.144^{*}$ & 0.921 & $24.21 \pm 0.33$ \\
50 DAS & & & \\
Shoot & $7.690^{*}$ & 5.985 & $28.49 \pm 0.71$ \\
Root & $2.055^{*}$ & 1.553 & $32.33 \pm 0.16$ \\
\hline
\end{tabular}

Source: ICRISAT; DAS: Days after sowing; SE: Standard error.

$32.33 \%$ heterotic advantage over inbred controls, while the corresponding values for shoot varied from 28.49 to $52.94 \%$. Saeki et al. (2016) postulated that once the shoot becomes photosynthetically active, the superiority of hybrid was linked with the increase in assimilation rate or leaf area ratio. They also reported that after the first week of germination, an increase in the number and size of photosynthetic palisade mesophyll cells was responsible for the expression of hybrid vigour in Chinese cabbage (Brassica rapa). Moreover, they hypothesized that an increase in the activities of chloroplast-targeted genes and their differential transcription levels could be important for establishing early stage heterosis.

In maize and sorghum (Sorghum bicolor), heterosis at seedling stage both for root and shoot is well documented under both normal and stress conditions. Chairi et al. (2016) observed that hybrids had higher plant height, shoot biomass and leaf area than their parents under both normal and limited water conditions. However, root weight and root length of hybrid seedlings were higher than parents especially under scarce water conditions. In another study, de Abreu et al. (2019) also reported heterosis in maize seedlings more expressively for root traits (root length and number of seminal roots) under water stress environment. Similarly in sorghum, the heterotic effects were recorded over the parents with respect to initial seedling vigour (reflected in shoot and root size), greater biomass and dry matter accumulation in hybrids. Yu and Tuinstra (2001) demonstrated that the sorghum hybrids exhibited greater tolerance to low temperature (chilling) during germination and seedling growth. From these studies it is concluded that during early plant growth the heterosis for root traits could play a significant role in encountering some stresses better than inbred lines.

\section{Hybrid advantage under disease stress}

Fusarium wilt (FW) and sterility mosaic (SM) are two major pigeonpea diseases. To assess the performance of pigeonpea hybrids under intense disease pressure both disease resistant hybrids and inbred cultivars were evaluated
Table 3. Performance ( $\mathrm{t} / \mathrm{ha}$ ) of hybrids and inbred varieties in disease-free and disease-sick fields at ICRISAT ${ }^{\#}$

\begin{tabular}{lcccccc}
\hline \multirow{2}{*}{ Genotype } & \multicolumn{3}{c}{ Disease-free field } & \multicolumn{3}{c}{ Disease-sick field } \\
\cline { 2 - 7 } & 1993 & 1994 & Mean & 1993 & 1994 & Mean \\
\hline Hybrids & & & & & & \\
IPH 1326 & 2.6 & 2.5 & 2.53 & 2.1 & 1.2 & 1.64 \\
IPH 1395 & 2.2 & 2.3 & 2.26 & 2.0 & 1.5 & 1.72 \\
IPH 1327 & 2.4 & 1.8 & 2.13 & 1.9 & 1.5 & 1.67 \\
Mean & 2.4 & 2.2 & 2.31 & 2.0 & 1.4 & 1.68 \\
\hline Inbreds & & & & & & \\
ICPL 87119 & 2.6 & 1.9 & 2.25 & 1.1 & 0.7 & 0.88 \\
ICPL 87051 & 1.5 & 1.6 & 1.60 & 1.3 & 0.9 & 1.11 \\
Mean & 2.05 & 1.75 & 1.93 & 1.2 & 0.8 & 1.00 \\
\hline Hyb adv (\%) & 17.1 & 25.7 & 19.7 & 66.7 & 75.0 & 68.0 \\
\hline
\end{tabular}

Source: ICRISAT; Hyb adv: Hybrid advantage.

\# SE or LSD not reported in data resources.

simultaneously in disease-sick and disease-free fields at ICRISAT, Patancheru (Hyderabad, India). Plant mortality in the susceptible controls in the sick-nursery ranged between 95-100\%, suggesting very high levels of virulent inoculums. At both the sites, all the test entries recorded $<1 \%$ disease score with respect to $\mathrm{FW}$ and SM diseases. The data recorded at the two testing environments showed large differences in grain productivity and hybrid vigour. In the disease-free field, the hybrids, on an average, produced $2.31 \mathrm{t} /$ ha yield and expressed $19.7 \%$ heterosis over the pure line cultivars (1.93 t/ha). On the other hand, under high disease pressure, although the overall productivity was relatively low (Table 3 ) but the mean heterosis (68\%) was three fold greater than that of disease-free conditions (ICRISAT, unpublished data). This experiment demonstrated that besides the genetic resistance for the two diseases, the hybrids also had additional resilience that enabled plants to produce more grains than inbred varieties under severe disease pressure. This ability of hybrids is likely to contribute positively towards negotiating the ill effects of diseases.

\section{Hybrid advantage under water-logging conditions}

Temporary water-logging causes $25-30 \%$ annual yield losses to pigeonpea (Sultana et al. 2013) particularly in the areas characterized by heavy rainfall and poor drainage. Under water logged situations, the anaerobic bacteria become active and deplete oxygen levels in the soil. As a consequence, the growth of pigeonpea plants is adversely affected, and sometimes it may also lead to plant mortality in patches. According to Sultana et al. (2013), pigeonpea hybrids in general exhibited greater tolerance to waterlogging than the pure line cultivars. It was observed that when the tolerant genotypes were exposed to extended water logging situations, the plants started producing aerenchyma cells, hypertrophied lenticels and subsequently adventitious roots. These special traits facilitate oxygen 
diffusion to the roots to restore respiration in the submerged plants (Armstrong 1979, Hingane et al. 2015). This in built survival mechanism in the hybrids along with greater resilience can negotiate the water-logging stress quite well to provide stability in pigeonpea production.

Hybrid advantage in adaptation and its on-farm validation

Pigeonpea hybrids in general show wider adaptation than inbred cultivars, and at most growing environments the hybrids have been found to out-yield the control cultivars (Saxena and Raina 2001, Saxena et al. 2018). Considering the requirements of crop diversification (Ali and Shivakumar 2005) pigeonpea breeders developed hybrids in the known three primary maturity groups for multilocation testing (Table 4). The sets of early maturing hybrids were tested at 25 locations across India. The top three hybrids were 'ICPH 2433' ( $2306 \mathrm{~kg} / \mathrm{ha})$, 'ICPH 2438' $(2127 \mathrm{~kg} / \mathrm{ha})$ and 'ICPH 2363 ' (2048 kg/ha), and they recorded $54 \%, 42 \%$, and $36 \%$ hybrid vigour over the best variety, respectively. In the medium duration group, hybrids such as 'ICPH 3491', 'ICPH 3497' and 'ICPH 3481' were found promising with $57 \%, 44 \%$ and $41 \%$ standard heterosis, respectively over 18 locations. In comparison to early and medium groups, the number of hybrids tested in the long-duration group was fewer, and their testing was done only at five locations. However, three hybrids 'ICPH 2307' (53\% heterosis), 'ICPH 2306' (39\% heterosis) and 'ICPH 2896 ' (38\% heterosis) exhibited significant hybrid vigour.

Lopez et al. (1996) reported that in comparison to inbred lines, the pigeonpea hybrids had greater productivity and adaptability under different moisture and soil regimes. Also, the pigeonpea hybrids exhibit a high level of plasticity, and this quality helps in providing crop coverage to the vacant field spaces caused by plant losses, thus avoiding the potential loss on account of reduced population.

Table 4. Hybrid advantage for yield recorded in early, medium and late maturity group hybrids in multi-location trials

\begin{tabular}{lcccc}
\hline \hline $\begin{array}{l}\text { Maturity } \\
\text { group }\end{array}$ & $\begin{array}{c}\text { Hybrid } \\
\text { number }\end{array}$ & $\begin{array}{c}\text { No. of } \\
\text { locations }\end{array}$ & $\begin{array}{c}\text { Mean yield } \\
(\mathrm{kg} / \mathrm{ha})\end{array}$ & $\begin{array}{c}\text { Standard } \\
\text { heterosis (\%) }\end{array}$ \\
\hline Early & ICPH 2433 & 25 & $2306^{* *}$ & 54 \\
& ICPH 2438 & 25 & $2127^{* *}$ & 42 \\
\multirow{4}{*}{ Medium } & ICPH 2363 & 25 & $2048^{* *}$ & 36 \\
& ICPH 3491 & 18 & $2919^{* *}$ & 57 \\
& ICPH 3497 & 18 & $2686^{* *}$ & 44 \\
\multirow{4}{*}{ Late } & ICPH 3481 & 18 & $2637^{* *}$ & 41 \\
& ICPH 2307 & 05 & $2855^{* *}$ & 53 \\
& ICPH 2306 & 05 & $2600^{* *}$ & 39 \\
& ICPH 2896 & 05 & $2579 * *$ & 38
\end{tabular}

** Significantly different from the corresponding check variety at $\mathrm{p}<0.01$.

Checks used: UPAS 120 (early); Asha (medium); Gwalior 3 (late).

Source: ICRISAT.
Chauhan et al. (1995) and Lopez et al. (1996) opined that besides key genetic factors responsible for the expression of hybrid vigour in pigeonpea, some other factors such as ability of hybrids to retain more moisture, production of greater root and shoot biomass, ability to combat various yield reducing stresses and speedy recovery from damages also contributed to the higher adaptation of pigeonpea hybrids. Parodi et al. (1983) and Kwon et al. (2002) concluded that homeostasis of heterosis with respect to stresses was associated with greater phenotypic stability in hybrids. Kočová et al. (2009) reported that the maize hybrids exhibited greater homeostatic (stable) heterosis for photosynthesis than its parents, resulting in the stable performance of hybrids. Aphalo et al. (1999) concluded that the stressed plants also use more energy in adjusting themselves to fit the stressed environments.

To demonstrate the on-farm validation, ICRISAT organized extensive pre-release on-farm testing of the three pigeonpea hybrids, namely 'ICPH 2671', 'ICPH 2740' and 'ICPH 3762'. All the on-farm trials were conducted by rainfed cultivators using the best local cultivar as control. Each trial was sown in one acre plot using locally recommended cultural practices. Although records of types and durations of stresses were not maintained, the crop might have experienced stresses as the rain-fed crop of pigeonpea is known to often encounter one or more biotic/abiotic stresses during its long growth cycle (Choudhary et al. 2011, 2013).

All the three hybrids expressed considerable heterosis for grain yield over the best local control, suggesting high adaptation of hybrids under diverse environments (Saxena and Tikle 2015). The hybrid 'ICPH 2671', released in the state of Madhya Pradesh, was evaluated in 1541 on farm trials in three states (Table 5), and its mean superiority over the control was 46.1\%. Another hybrid 'ICPH 2740', released in Andhra Pradesh, was tested in 87 trials in two states. On an average, this hybrid recorded $37.2 \%$ standard heterosis. For hybrid 'ICPH 3762', released in the state of Odisha, a total of 144 on-farm trials were organized in five districts, and the hybrid (1726 kg/ha), on an average,

Table 5. Yield $(\mathrm{kg} / \mathrm{ha})$ of three hybrids and control cultivar in the on-farm trials conducted under rain-fed conditions in different states

\begin{tabular}{llrrcc}
\hline \hline Hybrid & \multicolumn{1}{c}{ State } & $\begin{array}{c}\text { Farmers } \\
\text { (no.) }\end{array}$ & $\begin{array}{c}\text { Hybrid } \\
\text { yield }\end{array}$ & $\begin{array}{c}\text { Control } \\
\text { yield }\end{array}$ & $\begin{array}{c}\text { Hybrid } \\
\text { adv (\%) }\end{array}$ \\
\hline ICPH 2671 & Maharashtra & 782 & 969 & 717 & 35 \\
& Andhra Pradesh & 399 & 1411 & 907 & 55 \\
& Madhya & 360 & 1940 & 1326 & 46 \\
& Pradesh & & & & \\
& Total/mean & 1541 & 1437 & 983.3 & 46.1 \\
ICPH 2740 & Andhra Pradesh & 47 & 1999 & 1439 & 39 \\
& Gujarat & 40 & 1633 & 1209 & 35 \\
& Total/mean & 87 & 1816 & 1324 & 37.2 \\
ICPH 3762 & Odisha & 144 & 1726 & 813 & 112 \\
\hline
\end{tabular}

Source: ICRISAT. 
expressed $112 \%$ yield advantage over the best adapted cultivar. These outstanding performances demonstrated that the hybrids are widely adapted and can be a good option for enhancing the production and productivity of pigeonpea.

\section{Discussion}

Pigeonpea scientists are of opinion that there are two possible ways to increase the crop productivity, and these include restructuring plant type and exploitation of hybrid vigour. Therefore, to achieve a possible breakthrough, a complementary research is needed that would knit together these two and other important elements including genetic resistances and appropriate agronomy.

Restructuring of pigeonpea plant is a Herculean task, and so far the research carried out in this direction has not produced desired results (Bala Ravi 1983, Jain 1975, Singh et al. 2005). Being a short-day plant, pigeonpea produces plenty of biomass under normal rainy season (long-day) sowings. In contrast, in the short day post-rainy season (or delayed) sowings the biomass production is considerably reduced (Narayana and Sheldrake 1979, Roy Sharma et al. 1981). The pigeonpea physiologists postulate that inefficient partitioning in the rainy season crop and limited biomass in the post-rainy season crop are the primary yield limiting factors (Chauhan et al. 1995). Hence, for the postrainy cropping system, the cultivation of hybrids would be the right choice because these can produce $20-30 \%$ additional biomass. According to Chauhan et al. (1995), the hybrids in the rainy season have higher biomass and high crop growth rates, but the dry matter partitioning is similar to that of varieties; and these attributes make them a better choice as far as yield is concerned. In maize, sorghum and other cereals, hybrids have been reported to have high dry matter partitioning from source to sink. Hybrids also respond to high plant density due to lesser competition among themselves and higher tolerance to shading effects (Blum 2013). Such adaptive traits of hybrids need to be explored, assessed and exploited in pigeonpea as well.

Breeding for drought tolerance is a big challenge, particularly in a crop like pigeonpea where roots often grow $>2 \mathrm{~m}$ deep. Since pigeonpea takes a long time to mature, the crop encounters spells of intermittent droughts in both early and post-rainy seasons due to significant variations in the pattern and quantum of rainfall that is brought about by climate changes (Choudhary et al. 2018). The unpredictable arrival of monsoon and uncertain intermittent dry spells (particularly after the first rain) are most harmful to the crop as they adversely affect the seedling establishment and early growth. Lopez et al. (1996) and Chauhan et al. (1995) concluded that pigeonpea hybrid plants produced more grains than inbred cultivars even under drought environments because the hybrid plants retain relatively high water content than pure line varieties. It is therefore, reasonable to assume that in comparison to pure line pigeonpea cultivars the hybrids not only produce higher yields but also exhibit greater adaptation to drought situations, a characteristic which is otherwise difficult to improve through breeding. On the other hand, for breeding hybrids, the prerequisites breakthroughs have already been achieved (Saxena et al. 2018) and there is a need to exploit this technology at commercial level. Hathcock and McDaniel (1973) opined that the expression of heterosis even to a small magnitude for individual component characters is desirable for a crop. In case of pigeonpea, the hybrid vigour expressed in germination, seedling growth, root mass and tolerance to diseases and water-logging can help the rainfed crop in negotiating some of the yield reducing stresses well enough to enhance its productivity and stability.

According to Hoecker et al. (2006), the manifestation of heterosis starts during very early stage of root development, perhaps soon after germination. Therefore, the young root system may be considered a suitable model for key molecular studies to understand the process of manifestation of heterosis during seedling development. Heterosis in seedling size was found to be linked to heterosis in the rate of cell division; and the genetic information is set in the seed embryo and expressed several days after fertilization (Meyer et al. 2007). These biological processes also have corresponding effects on the following cell division and organ differentiation. The rapid cell division also depends on plant energy resources and assimilation. Finally, the metabolic enhancements induced by heterosis result into large biomass (Goff 2011). Araus et al. (2010), Blum et al. (1977), and Blum (2013) opined that the large roots and associated greater water use in maize hybrids is not driving heterosis rather being the result of heterosis. The high rates of associated metabolic and physiological events provide the required energy to take care of both sustaining cell division as well as large sink which confer adaptive advantage to hybrids under diverse growing conditions.

'Heterotic' homeostasis under temporal abiotic stresses is associated with greater phenotypic stability in hybrids (Kwon et al. 2002, Parodi et al. 1983). Aphalo et al. (1999) concluded that the stressed plants also use more energy in adjusting themselves to fit in the stress environments. Kočová et al. (2009) reported that in maize hybrids homeostatic (stable) heterosis is exhibited for photosynthesis which provides stability to the performance. These heterotic advantages could have made pigeonpea hybrids more efficient in negotiating abiotic stresses than the inbred cultivars.

\section{Concluding remarks}

Breeders are under pressure the world over to improve pigeonpea productivity which has been static around 700$800 \mathrm{~kg} / \mathrm{ha}$ for decades despite release of a number of highyielding cultivars in many countries of Asia and east Africa. The major constraint relates to its cultivation largely under rainfed situation, which in turn leads it to face various biotic and abiotic stresses. The preceding discussion 
indicates that manifestation of heterosis in pigeonpea hybrids starts with the development of embryonic root itself. Hybrid vigour expressed as seedling vigour, improved seedling biomass (root and shoot), greater resilience and heterotic advantage in adaptation help hybrids to negotiate one or more abiotic and biotic stresses better than the pure line cultivars. However, for long-term sustainability of hybrid breeding program in pigeonpea, it is imperative that superior hybrids are bred at regular intervals. To this endeavour, pigeonpea breeders need to develop improved hybrid male and female parents with high combining ability, resistance or tolerance to various biotic and abiotic stresses including market-preferred seed traits.

Commercial exploitation of heterosis in pigeonpea is a recent phenomenon. In maize, hybrids have shown photosynthetic homeostasis under suboptimal environmental situations, tolerance to crowding and shading stresses, lesser inter plant competition, improved dry matter partitioning and large sink. Although pigeonpea is a non-determinate crop having high outcrossing rates, the lesson learnt from 'heterotic' maize can be applied to design and develop 'efficient' pigeonpea hybrids capable of coping with multiple biotic and abiotic stress conditions occurring in the field. Extensive area coverage under such hybrids might lead to a quantum jump in pigeonpea productivity.

\section{Author Contribution Statement}

KBS and AKC conceived the idea. KBS developed the blueprint of the MS, while AKC, RKS and YSC provided substantial inputs to the initial draft of the MS. KBS and AKC finalized the MS for submission.

\section{Acknowledgment}

We gratefully acknowledge Pigeonpea Breeding Unit of ICRISAT, Hyderabad (India) for providing access to its published and unpublished data resources.

\section{Literature Cited}

Ali, M. and B.G. Shivakumar (2005) Cropping system research in pigeonpea. In: Ali, M. and S. Kumar (eds.) Advances in Pigeonpea Research, Indian Institute of Pulses Research, Kanpur, 208024 India, pp. 164-181.

Aphalo, P.J., C.L. Ballare and A.L. Scopel (1999) Plant-plant signalling, the shade avoidance response and competition. J. Exp. Bot. 50: 1629-1634.

Araus, J.L., C. Sánchez and L. Cabrera-Bosquet (2010) Is heterosis in maize mediated through better water use? New Phytol. 187: 392 406.

Armstrong, W. (1979) Aeration in higher plants. Adv. Bot. Res. 5: 225-332.

Bala Ravi, S. (1983) A breeding approach for improvement of plant type and yield. Proceedings of Joint FAO/IAEA Meeting (Divison of Isotope and Radiation, Application of Atomic Energy for Food and Agriculture Development, Vienna, Austria), pp. 67-104.
Bharathi, M. and K.B. Saxena (2012) A comparative study of hybrids and inbred cultivars for germination and other related traits of pigeonpea. J. Food Leg. 25: 351-354.

Blum, A., W.R. Jordan and G.F. Arkin (1977) Sorghum root morphogenesis and growth II. Manifestation of heterosis. Crop Sci. 17: 153-157.

Blum, A. (2013) Heterosis, stress, and the environment: a possible road map towards the general improvement of crop yield. J. Exp. Bot. 64: 4829-4837.

Carver, K.M., M.G. Mula, D.P. Thakare, A. Rathore, R. Das and R.V. Kumar (2014) Response of germination to seed size and color of pigeonpea (Cajanus cajan (L.) Millsp.). Green Farming 5: 372376.

Chairi, F.C., A. Elazab, R. Sanchez-Bragado, J.L. Araus and M.D. Serret (2016) Heterosis for water status in maize seedlings. Agric. Water Manag. 164: 100-109.

Chauhan, Y.S., C. Johansen and K.B. Saxena (1995) Physiological basis of yield variation in short duration pigeonpea grown in different environments of the semi-arid tropics. J. Agron. Crop Sci. 174: $163-174$.

Choudhary, A.K., R. Sultana, A. Pratap, N. Nadarajan and U.C. Jha (2011) Breeding for abiotic stresses in pigeonpea. J. Food Leg. 24: $165-174$.

Choudhary, A.K., S. Kumar, B.S. Patil, M. Sharma, S. Kemal, T.P. Ontagodi, S. Datta, P. Patil, S.K. Chaturvedi, R. Sultana et al. (2013) Narrowing yield gaps through genetic improvement for fusarium wilt resistance in three pulse crops of the semi-arid tropics. SABRAO J. Breed. Genet. 45: 341-370.

Choudhary, A.K., R. Sultana, M.I. Vales, K.B. Saxena, R.R. Kumar and P. Ratnakumar (2018) Integrated physiological and molecular approaches to improvement of abiotic stress tolerance in two pulse crops of the semi-arid tropics. Crop J. 6: 99-114.

Dahal, D., B.P. Mooney and K.J. Newton (2012) Specific changes in total and mitochondrial proteomes are associated with higher levels of heterosis in maize hybrids. Plant J. 72: 70-83.

de Abreu, V.M., E.V.R. Von Pinho, M.P. Mendes-Resende, M. Balestre, A.C. Lima, H.O. Santos and R.G. Von Pinho (2019) Combining ability and heterosis of maize genotypes under water stress during seed germination and seedling emergence. Crop Sci. 59: $33-43$.

Donaldson, C. and G.E. Blackman (1974) The initiation of hybrid vigour in Zea mays during the germination phase. Ann. Bot. 38: 515-527.

FAOSTAT (2019) URL: http://www.faostat3.fao.org.

Goff, S.A. (2011) A unifying theory for general multigenic heterosis: energy efficiency protein metabolism, and implications for molecular breeding. New Phytol. 189: 923-937.

Hathcock, B.R. and M.E. McDaniel (1973) Yield and yield component heterosis in Avena hybrids. Crop Sci. 13: 8-10.

Hingane, A.J., K.B. Saxena, S.B. Patil, R. Sultana, S. Srikant, N. Mallikarjuna, R.V. Kumar and C.V.S. Kumar (2015) Mechanism of water-logging tolerance in pigeonpea. Indian J. Genet. Plant Breed. 75: 208-214.

Hoecker, N., B. Keller, H.P. Piepho and F. Hochholdinger (2006) Manifestation of heterosis during early maize (Zea mays L.) root development. Theor. Appl. Genet. 112: 421-429.

Jahnke, S., B. Sarholz, A. Thiemann, V. Kühr, J.F. Gutiérrez-Marcos, H.H. Geiger, H.P. Piepho and S. Scholten (2010) Heterosis in early seed development: a comparative study of $F_{1}$ embryo and endosperm tissues 6 days after fertilization. Theor. Appl. Genet. 120: $389-400$. 
Jain, H.K. (1975) Breeding for yield and other attributes in grain legumes. Indian J. Genet. Plant Breed. 35: 169-187.

Kočová, M., D. Holá, N. Wilhelmová and O. Rothavá (2009) The influence of low-temperature on the photochemical activity of chloroplasts and activity of antioxidant enzymes in maize leaves. Biol. Plant. 53: 475-483.

Kwon, S.J., S.N. Ahn, E.G. Joeng, Y.H. Jeon, H.G. Hwang, H.C. Choi and H.P. Moon (2002) Relationship between genetic divergence and hybrid performance in japonica rice grown in a cold waterirrigated field. Euphytica 128: 389-396.

Lopez, F.B., C. Johansen and Y.S. Chauhan (1996) Effects of drought stress on phenology, yield, and yield components timing in short duration pigeonpea. J. Agron. Crop Sci. 177: 311-320.

Mercer, K.L., R.G. Shaw and D.L. Wyse (2006) Increased germination of diverse crop-wild hybrid sunflower seeds. Ecol. Appl. 16: 845-854.

Meyer, S., H. Pospisil and S. Scholten (2007) Heterosis associated gene expression in maize embryos 6 days after fertilization exhibits additive, dominant and over dominannt pattern. Plant Mol. Biol. 63: 381-391.

Mino, M. (1980) Hybrid vigor found in some characters of maize seedlings. Japan. J. Breed. 30: 131-138.

Mula, M.G., D.P. Thakare, S.P. Mehtre and A. Rathore (2015) Evaluation for early seedling vigour of hybrids and varieties of pigeonpea (Cajanus cajan (L.) Millsp.). Green Farming 6: 1-4.

Narayana, A. and A.R. Sheldrake (1979) Pigeonpea ((Cajanus cajan (L.) Millsp.) as a winter crop in peninsular India. Exp. Res. 15: 91-95.

Parodi, P.C., W.E. Nyquist, F.L. Patterson and H.F. Hodges (1983) Traditional combining-ability and Gardner-Eberhart analyses of a diallel for cold resistance in winter wheat. Crop Sci. 23: 314-318.

Rajjou, L., M. Duval, K. Gallardo, J. Catusse, J. Bally, C. Job and D. Job (2012) Seed germination and vigor. Annu. Rev. Plant Biol. 63: 507-533.

Romagnoli, S., M. Maddaloni, C. Livini and M. Motto (1990) Relationship between gene expression and hybrid vigor in primary root tips of young maize (Zea mays L.) plantlets. Theor. Appl. Genet. 80: 769-775.

Roy Sharma, R.P., H.C. Thakur and H.M. Sharma (1981) Pigeonpea as a rabi crop in India. Proceedings of International Workshop on Pigeonpeas, International Crops Research Institute for the Semi Arid Tropics, Patancheru, 1: 26-36.

Saeki, N., T. Kawanabe, H. Ying, M. Shimizu, M. Kojima, H. Abe, K. Okazaki, M. Kaji, J.M. Taylor, H. Sakakibara et al. (2016) Molecular and cellular characteristics of hybrid vigour in a commercial hybrid of Chinese cabbage. BMC Plant Biol. 16: 45.

Saxena, K.B., Y.S. Chauhan, C. Johansen and L. Singh (1992) Recent developments in hybrid pigeonpea research. In: New Frontiers in Pulses Research and Development, Directorate of Pulses Research, Kanpur 208 024, India, pp. 58-69.

Saxena, K.B. and R. Raina (2001) Pattern analysis for genotype by environment effects for seed weight and grain yield in pigeonpea hybrids. Indian J. Genet. Plant Breed. 61: 226-231.

Saxena, K.B. (2008) Genetic improvement of pigeonpea-a review. Trop. Plant Biol. 1: 159-178.

Saxena, K.B. and A.N. Tikle (2015) Believe it or not, hybrid technology is the only way to enhance pigeonpea yields. Int. J. Sci. Res. 5: 1-7.

Saxena, K.B., D. Sharma and M.I. Vales (2018) Development and commercialization of CMS pigeonpea hybrids. Plant Breed. Rev. 41: 103-167.

Singh, N.B., I.P. Singh and B.B. Singh (2005) Pigeonpea breeding. In: Ali, M. and S. Kumar (eds.) Advances in Pigeonpea Research, Indian Institute of Pulses Research, Kanpur 208 024, India, pp. 67-95.

Sultana, R., M.I. Vales, K.B. Saxena, A. Rathore, S. Rao, S.K. Rao, M.G. Mula and R.V. Kumar (2013) Waterlogging tolerance in pigeonpea (Cajanus cajan (L.) Millsp.): genotypic variability ansuppd identification of tolerant genotypes. J. Agric. Sci. 151: 659-671.

Thakare, D.P., M.G. Mula, S.P. Mehtre, K.B. Saxena and A. Rathore (2013) Seedling vigour study in pigeonpea ((Cajanus cajan (L.) Millsp.) hybrids and varieties. J. Food Leg. 26: 100-102.

WorldAtlas (2019) https://www.worldAtlas.com (Accessed on January 06, 2020)

Yu, J. and M.R. Tuinstra (2001) Genetic analysis of seedling growth under cold temperature stress in grain sorghum. Crop Sci. 41: 1438-1443. 